\title{
Cutaneous gastrocolic fistula as a complication of percutaneous endoscopic gastrostomy
}

\author{
Pedro Imbeth-Acosta ${ }^{1}$, Mario Pineda ${ }^{2}$, Zulay Mondol-Almeida ${ }^{2}$, Alejandro Blanquicett ${ }^{3}$, \\ Kevin Llanos-Almario ${ }^{2}$, and Maria Cristina Martinez Avila ${ }^{4}$ \\ ${ }^{1}$ Nuevo Hospital Bocagrande \\ ${ }^{2}$ Universidad del Sinu Elias Bechara Zainum Facultad de Ciencias de la Salud \\ ${ }^{3}$ Corporación Universitaria Rafael Nuñez \\ ${ }^{4}$ Rosario University
}

November 24, 2021

\begin{abstract}
Gastrocolic fistulas represent a serious but rare complication of Percutaneous endoscopic gastrostomy (PEG). A 90-year-old male with multiple comorbidities and high preoperative risk develops one. He was successfully treated with expectant management.
\end{abstract}

\section{Cutaneous gastrocolic fistula as a complication of percutaneous endoscopic gastrostomy}

Pedro Luis Imbeth-Acosta ${ }^{1}$, Mario Pineda ${ }^{2}$, Zulay Mondol-Almeida ${ }^{2}$, Alejandro Blaquicett ${ }^{3}$, Kevin Llanos $^{2}$, María Cristina Martínez-Ávila ${ }^{4^{*}}$

${ }^{1}$ Department of Gastroenterology. Nuevo Hospital Bocagrande. Cartagena, Colombia

${ }^{2}$ Department of Internal Medicine. Universidad del Sinú. Cartagena, Colombia

${ }^{3}$ Department of Internal Medicine. Corporación Universitaria Rafael Núñez. Cartagena, Colombia

${ }^{4}$ Department of Epidemiology. Nuevo Hospital Bocagrande. Cartagena, Colombia

Correspondence author: María Cristina Martínez-Ávila.Cristina.martinezavila@gmail.com

Key Clinical Message: Gastrocolic fistulas could be fatal in determined patients, surgical treatment is usually offered. However, conservative therapeutic strategies are also to be considered specially in high-risk patients.

Abstract: Gastrocolic fistulas represent a serious but rare complication of Percutaneous endoscopic gastrostomy (PEG). A 90-year-old male with multiple comorbidities and high preoperative risk develops one. He was successfully treated with expectant management.Key words: gastrocolic fistulas, gastrostomy, complication

Case description: A 90-year-old male with dependence for basic activities due neuromotor sequelae of cerebrovascular accident, presented with 24-hours history of tonic-clonic seizures and fever. Chest X-ray revealed an infiltrate in the upper lobe of the right lung. He was diagnosed with bronchial-aspiration pneumonia and oropharyngeal dysphagia. Percutaneous endoscopic gastrostomy (PEG) was performed. 12 hours after the procedure, pain and abdominal distension began, showing an area of peristomal induration. Abdominal-CT (Figure 1) reveals pneumoperitoneum, gastrostomy catheter through the transverse colon located in the 
gastric lumen (gastrocolic fistula). Even though the high-risk, conservative treatment was maintained expecting the formation of a fistulous tract and antibiotic was prescribed. His condition gradually improved, until complete resolution was achieved.

PEG is a minimally invasive technique used for permanent enteral feeding ${ }^{1}$. Gastrocolic fistulas represent a serious but rare complication of PEG associated with a high morbimortality rate ${ }^{2}$. They can be asymptomatic, present diarrhea, abdominal pain, distension, fecaloid vomiting, peritonitis. CT allows visualization of the fistula ${ }^{1}$. Treatment consists in resection of the fistula and surgical gastrostomy. High-risk patients deserve individualized management, which may even reduce the need for surgical intervention; timely referral to a specialized center has repercussions on the evolution and prognosis ${ }^{2}$.

Acknowledgements Written informed consent was obtained from the patient to publish this report in accordance with the journal's patient consent policy

\section{Conflict of interest}

No competing interests to declare.

Author contributions $\mathrm{AB}$ and MCMA: drafted the manuscript. ZMA and MP: revised the manuscript. PLIA: treated the patient. All authors read and approved the final version and agree to be accountable for all aspects of the work.

\section{Ethical approval}

The authors declare no funding was received for this research. No patient identifying data has been released in the article.

Bibliography1. Kurien M, McAlindon ME, Westaby D et al. Percutaneous endoscopic gastrostomy feeding. BMJ 2018; 340: 1074-1078. 2. Martinez-Ordaz JL, Luque-de-Leon E, Suarez-Moreno RM et al. Postoperative enterocutaneous fistulas. Gaceta Medica de Mexico 2020; 139 (2).

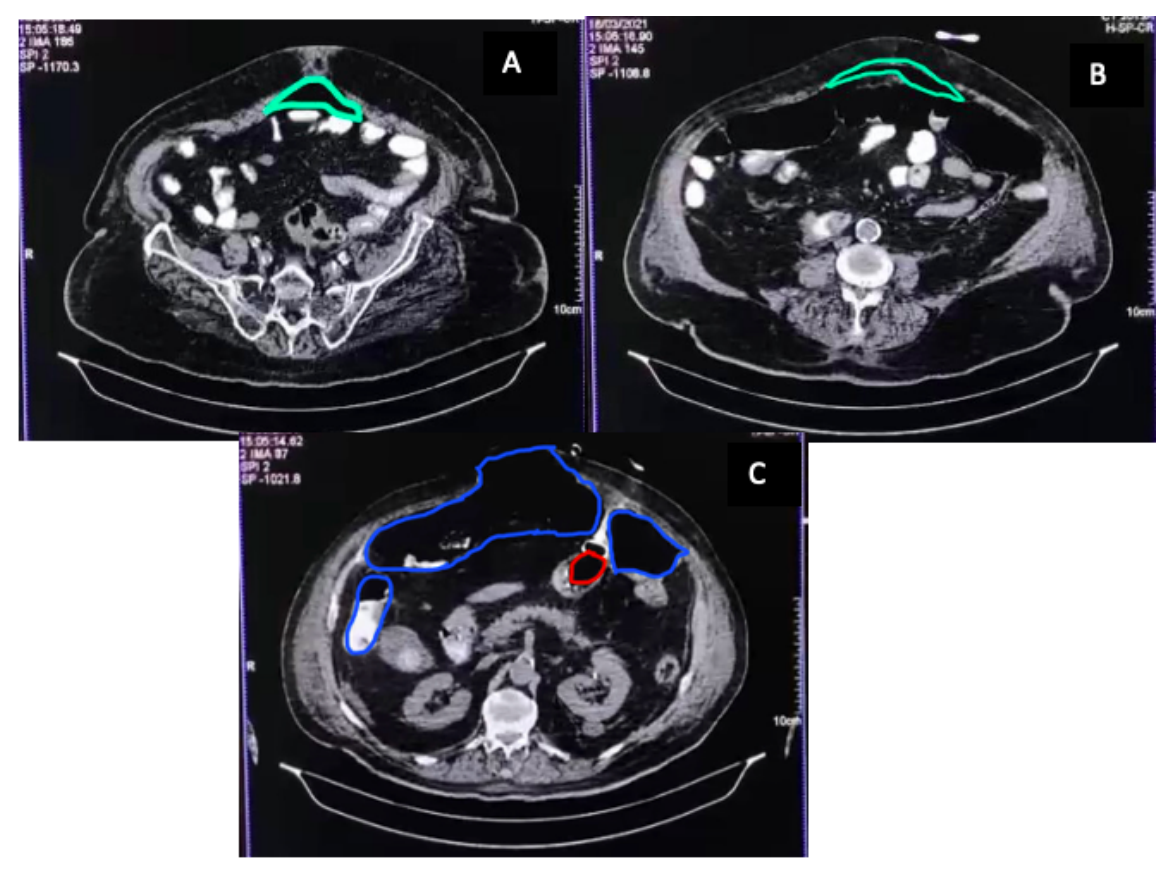

